\title{
A New Device Based on Interferometric Optical Detection Method for Label-Free Screening of C-Reactive Protein
}

\author{
María V. Maigler, Miguel Holgado, María Fe Laguna, Francisco J. Sanza, Beatriz \\ Santamaría, Alvaro Lavin, and Rocio L. Espinosa
}

\begin{abstract}
In previous work, the performance of a compact and cost-effective point-of-care (PoC) device based on the increase relative optical power (IROP) methodology is reported and it is determined the enhancement in comparison with standard high-resolution spectrometry in terms of limit of detection. This paper describes a new label-free IROP-based biomedical device capable of working with low concentration of reagents and low sample volume per measurement in order to be used for screening different steps necessary in immunoassay optimization. This new approach significantly improves the sensing performance in terms of read-out signal ( $\triangle \mathrm{IROP})$ per nanometer of biofilm in comparison with our previous work. This improvement is achieved due to the implementation of a laser as light source of the optical read-out system and the redesign of Fabry-Perot transducers by optimizing their reflectivity response and reducing their sensing area. For demonstrating the screening capability of this new PoC device in several immunoassays steps and methodologies, a $\mathrm{C}$-reactive protein detection assay was carried out as a potential application and assay model. It is remarkable that only $10 \mu \mathrm{L}$ of sample was used per measurement. This labelfree IROP-based device complies an easy-to-use and cost-effective tool for immunoassays optimization in terms of performance, reagents cost, and measuring time.
\end{abstract}

Index Terms-C-reactive protein (CRP), label-free optical biosensors, point-of-care (PoC) devices, screening of immunoassays.

\section{INTRODUCTION}

I MMUNOASSAYS techniques based on the specific interaction of an antigen and an antibody are widely used as a diagnosis technique in many fields, from molecular biology to environmental science. They present several advantages such as specificity, high throughput, and high sensitivity for a wide range of analytes, but also some challenges as the reagent cost, volume sample, and the labeling process for standard techniques [enzyme-linked immunosorbent assay (ELISA), western blotting, and immunochemistry] [1]. Optical labelfree biosensors aim to overcome these challenges, avoiding the labeling process and offering other advantages in terms of simplicity or measuring time and the capability to monitor every step in the immunoassay procedure, creating a great tool for molecular binding screening [2]-[5]. Therefore, optical label-free biosensors represent a relevant and constantly growing topic in several fields, such as food control and environmental monitoring [6]-[12], drug control [13], [14], medical diagnosis [15], [16], or biochemical monitoring [17]-[20].
This paper reports a cost-effective tool for the optimization of label-free immunoassays that enhances the biomolecules recognition performance reported in previous work, as well as reduces significantly the sample volume needed per measurement in comparison with goal standard techniques such as lateral flow [21], ELISA, or surface plasmon resonancebased devices [22]-[24]. It is worthy to mention here that reducing the amount of sample volume, as well as the chemical reagents needed for developing the diagnostic results, will permit to diminish the time for obtaining the screening results in a cost-effective manner. Moreover, when an immunoassay has to be designed for detecting a target biomolecule, all the necessary steps related to the immobilization of bioreceptors onto the sensing surface, the blocking agents to avoid the unspecific bounding, and the effectiveness of the recognition need to be optimized. The goal of this paper is to present an efficient biomedical device for optimizing the immunoassays development by using low volume of reagents in a label-free approach. To demonstrate this, it is performed the optimization steps for developing the screening of a direct label-free immunoassay for the recognition of C-reactive protein (CRP). This protein is a well-known biomarker for inflammatory, cardiovascular, and infections processes, as well as for other applications such as Crohn's disease or Colon cancer [25], [26] and its detection has been the goal for several diagnosis devices developed over the years [27]-[32].

\section{BACKGROUND THEORY}

Previous works [33], [34] reported in detail, the increased relative optical power (IROP) methodology that quantifies the biomolecule accumulation or recognition in the sensing area. 
In these publications, the IROP (\%) signal (2) is calculated as a function ( $f_{\text {TRANS }}$ ) defined as the quotient of the optical power measured in two Fabry-Perot (FP) interferometers, signal $\left(I_{\text {Sig }}\right)$ and reference $\left(I_{\text {Ref }}\right)$, for a specific optical interrogation band $\left(\mathrm{wn}_{1}, \mathrm{wn}_{2}\right)(1)$

$$
\begin{aligned}
f_{\text {TRANS }\left[\mathrm{wn}_{1}, \mathrm{wn}_{2}\right]} & =\frac{I_{\text {Sig }}\left[w n_{1}, w n_{2}\right]}{I_{\text {Ref }}\left[w n_{1}, w n_{2}\right]} \\
\operatorname{IROP}(\%) & =\left(f_{\text {TRANS }}-1\right) \cdot 100 \\
& =\left[\left(\frac{I_{\text {Sig }}}{I_{\text {Ref }}}\right)-1\right] \cdot 100 .
\end{aligned}
$$

In addition, the $\triangle \mathrm{IROP}(\%)$ value is described as follows, and it is defined as the variation in the optical read-out for signal interferometer due to the biomolecule accumulation or recognition on the sensing surface:

$$
\Delta \operatorname{IROP}(\%)=100 \cdot\left(\frac{I_{\text {Sig }}^{n}-I_{\text {Sig }}^{0}}{I_{\text {Ref }}}\right) .
$$

In the new approach detailed within this paper, the light source for the optical interrogation of both signal and reference FP interferometers is an infrared laser diode module (UL5-3.5G-850-C-E World Star Tech), which substitute the LED used in our former publications. The laser emission spectral range is between 846.2 and $846.6 \mathrm{~nm}\left(11817.5 \mathrm{~cm}^{-1}\right.$ $11811.9 \mathrm{~cm}^{-1}$ ). Therefore, the optical interrogation band is reduced from $56 \mathrm{~nm}$ in the LED system to $0.4 \mathrm{~nm}$ in this new approach and it is now narrow enough to interrogate the signal interferometer at the maximum slope of its reflectivity spectrum. This enhancement in the optical interrogation band translates in a major variation in the optical power before and after the biomolecule accumulation on the sensing surface $\left(I_{\text {Sig }}^{\mathrm{n}}-I_{\text {Sig }}^{0}\right)$, in comparison with our previous work.

Regarding the reference interferometer implemented in this new approach, an optimized redesign based on a thin film of $526 \mathrm{~nm}$ of silicon nitride $\left(\mathrm{Si}_{3} \mathrm{~N}_{4}\right)$ over a $\mathrm{Si}$ substrate allows the interrogation on the minimum reflectivity signal. The minimum optical power measured in the reference interferometer $\left(I_{\text {Ref }}\right)$ combined with the interrogation of the signal interferometer at its maximum slope $\left(I_{\mathrm{Sig}}\right)$ translates in a considerable enhancement in the system performance for screening the read-out signal variations during the interrogation process.

In order to characterized this new device and obtain the experimental signal of $\triangle I R O P(\%)$ and the system sensitivity (see Fig. 1), it is used the same methodology as previously reported, which consists on fabricating several FP interferometers of $\mathrm{Al}_{2} \mathrm{O}_{3}$ over a $\mathrm{Si}$ substrate using atomic layer deposition (ALD) technique. The interferometers fabricated present increasing thicknesses of $\mathrm{Al}_{2} \mathrm{O}_{3}(2.5,5,10$, and $20 \mathrm{~nm})$ and can be used to simulate thin layers of biofilm.

Bruker Vertex 70, a Fourier transform visible and infrared spectrometer (FTIR-VIS) is used for the characterization of these $\mathrm{Al}_{2} \mathrm{O}_{3}$ interferometers as well as the reference interferometer. In addition, the experimental emission spectra in the wavelength of both lasers included in signal and reference optical channels are obtained using a high-resolution CCD spectrometer (Mightex Systems) [Fig. 1(a) and (b)]. These spectra
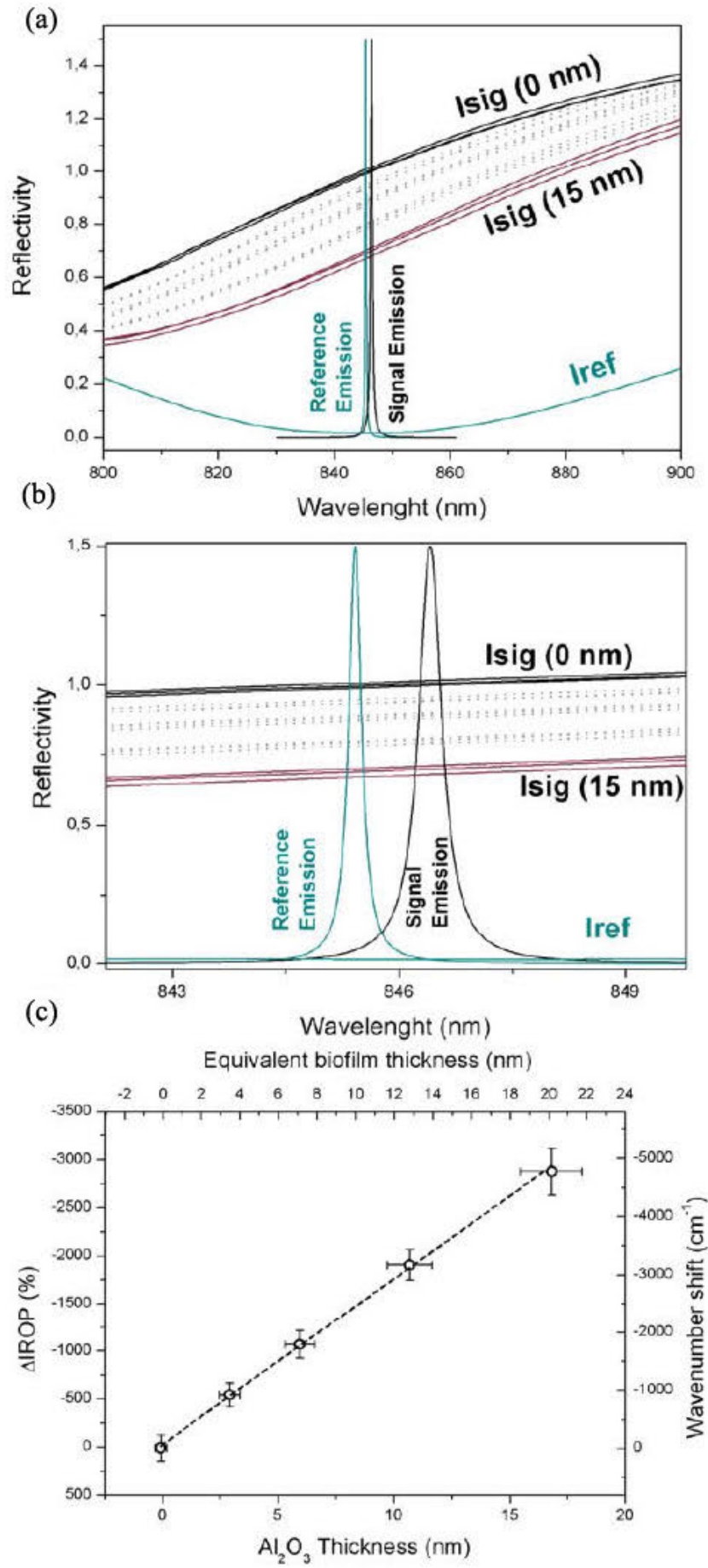

Fig. 1. (a) and (b) Experimental spectra, obtained using FTIR-VIS spectrometer, for FP interferometers with $I_{\text {sig }}(0 \mathrm{~nm})$ being the spectrum for an FP interferometer with $0 \mathrm{~nm}$ of $\mathrm{Al}_{2} \mathrm{O}_{3}$ and $I_{\text {sig }}(15 \mathrm{~nm})$ the spectrum of an $\mathrm{FP}$ interferometer with $15 \mathrm{~nm}$ of $\mathrm{Al}_{2} \mathrm{O}_{3}$. The spectra curves between these two represent increasing thickness of $\mathrm{Al}_{2} \mathrm{O}_{3}$ between 0 and $15 \mathrm{~nm}$. It also presents the emission spectra for the laser diodes implemented in signal and reference optical channels. (c) $\triangle$ IROP (\%) read-out signal calculated from the experimental spectra curves in (a), and represented as a function of the $\mathrm{Al}_{2} \mathrm{O}_{3}$ thickness and the equivalent biofilm thickness.

allow to infer the thickness of the $\mathrm{Al}_{2} \mathrm{O}_{3}$ deposited by ALD, assuming a refractive index between $n=1.65$ and $n=1.76$ as reported for this fabrication technique [35], [36].

Although the absolute $\mathrm{Al}_{2} \mathrm{O}_{3}$ thickness is not the goal of this paper, it is needed in order to evaluate the sensing performance 
of the device and to define the slope of the sensing response curve [Fig. 1(c)]. This estimation is also used to calculate the equivalent biofilm thickness for this FP interferometers, considering a refractive index $n=1.42$, as it is usually employed [37].

Therefore, by measuring the reflectivity profile of each $\mathrm{Al}_{2} \mathrm{O}_{3}$ interferometer and inferring its thickness, as well as measuring the reference interferometer $\left(\mathrm{Si}_{3} \mathrm{~N}_{4}\right)$ spectrum along with the experimental emission for both optical channels, (3) can be resolved to obtain the $\triangle$ IROP read-out signal as a function of the $\mathrm{Al}_{2} \mathrm{O}_{3}$ thickness and the equivalent biofilm thickness [Fig. 1(c)].

As a result, for this case of study, the sensitivity defined as the slope of the $\triangle$ IROP (\%) signal as a function of the biofilm thickness (nanometer) is $145.35 \% \Delta$ IROP per nanometer of biofilm, in comparison with the sensitivity obtained for our previous work and calculated as 3.079\% $\Delta$ IROP per nanometer of biofilm.

In order to obtain the limit of detection (LoD) of the device, the expanded uncertainty is calculated as presented in the following equation:

$$
U=3 \cdot \overline{\frac{s^{2}}{n}+\frac{\left(\Delta_{\text {IROP-RES }}\right)^{2}}{12} .}
$$

In this equation, $\Delta_{\text {IROP-RES }}$ can be calculated as in (5), where $\left(A D C_{R E S}\right)$ is the resolution of the analog-to-digital converter. This calculation resolves in a value of 0.0012 for $\left(\Delta_{\text {IROP-RES }}\right)^{2} / 12$. Therefore, this value is negligible in comparison with the experimental standard deviation value calculated for the nine repeated measurements carried out by the read-out device in each sensing cell (SC). This standard deviation leads to an expanded uncertainty value of $3.35 \%$

$$
\left(\Delta_{\text {IROP-RES }}\right)^{2}=\frac{2 \cdot 100}{I_{\text {Ref }}}\left(\frac{\partial I_{\text {Sig }}}{\partial R_{\text {Sig }}}\right) R_{\text {Sig }}^{2}=\frac{2 \cdot 100}{I_{\text {Ref }}}\left(\mathrm{ADC}_{\text {RES }}\right)^{2} .
$$

In addition, the LoD can be calculated as the expanded uncertainty divided by the experimental sensitivity, which resulted in LoD of $0.02 \mathrm{~nm}$ of biofilm.

\section{A. Biotransducers Design and Fabrication- KITs Implementation}

As stated previously, the IROP-based system developed in this paper requires two interferometers (signal and reference) to carry out the measurement. The reference interferometer has been already described but the signal interferometer presents a different configuration in order to be able to carry out the accumulation and recognition of biomolecules with the highest sensitivity and using low reagents concentration and volume.

Signal transducer consists of three SCs. When a bioreceptor is attached on the SCs for recognizing specifically a target biomolecule, these biotransducers are called BICELL (Biophotonic SCs) [38]. For this paper, the dimension of each BICELL has been reduced to only $100 \mu \mathrm{m}$ of diameter and made of a SU-8 resist plus a very thin film of nitrocellulose suitable for biomolecules adsorption. This stack of thin layers is over a thin layer of $\mathrm{SiO}_{2}$ and a $\mathrm{Si}$ substrate, forming a

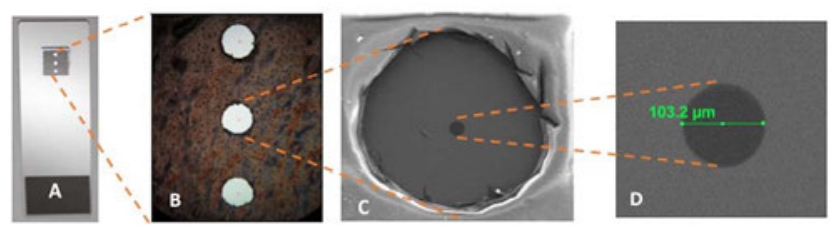

Fig. 2. (A) Optical image of a glass substrate KIT with a chip of three wells. (B) Optical image of the chip with the three wells. (C) SEM image of a single well with the FP transducer or SC in the middle. (D) SEM micrograph with the FP transducer circle shaped with a diameter of only $100 \mu \mathrm{m}$.

well (see Fig. 2). The fabrication steps for these BICELLs are described in detail in [39]. However, the reason for the reduction of the SCs diameter to $100 \mu \mathrm{m}$, instead of $800 \mu \mathrm{m}$, is justified by the expected improvement in concentration sensitivity when reducing the volume of sample deposited in each well. This is because for a given sample volume, the lower the size of the sensing area, the higher the concentration of biomolecules on that sensing area, in terms of an absolute number of biomolecules per area, and finally, the higher the equivalent biofilm thickness [40].

Once the transducer is fabricated and implemented in a glass substrate to ease its manipulation, it confirms a KIT, which is validated by measuring the interference response of each SC using a high-resolution FTIR-VIS spectrometer.

\section{B. Description of the Optical Read-Out Device}

The optical read-out device consists of two identical optical systems to carry out the FP signal and reference interferometers interrogation simultaneously and an electromechanical system to be able to interrogate several consecutive SCs in a single measurement. Fig. 3 shows a technical drawing of the device with its main components.

In order to be capable of reading SCs of $100 \mu \mathrm{m}$, a laser diode module substitutes the LED used as light source for the previous platform [1]. This laser module includes customized optics to reach a $60-\mu$ m-diameter spot at a working distance of $35 \mathrm{~mm}$. The photoreceptor selected (S2386-18L Hamamatsu) completes the optical system, with a configuration of $13^{\circ}$ between both components.

The electromechanical system consists of high-precision linear guideways to go through $x$ - and $y$-axis, connected to stepper motors and controlled by the electronic system integrated in a single board. These elements combined reach a resolution of five micrometers in both axes. As presented previously, the KIT consists of three SCs of $100 \mu \mathrm{m}$ of diameter over an antireflective coating based on $215 \mathrm{~nm}$ of $\mathrm{SiO}_{2}$. The system developed carries out the measurement of the SC within the kit sequentially and it utilizes the signal contrast between the SC and the antireflective coating as a positioning feedback. The XY-positioning system allows scanning the reflective signal of the complete KIT and localizes the exact position of the center of the SC.

\section{Immunoassay Procedure}

A direct immunoassay is performed for the recognition of CRP where the SC surface is biofunctionalized with a linker protein (A-protein) [41], followed by the anti-C-reactive antibody and a blocking step with polyvinylpyrrolidone [42] to avoid unspecific absorption. 
(a)

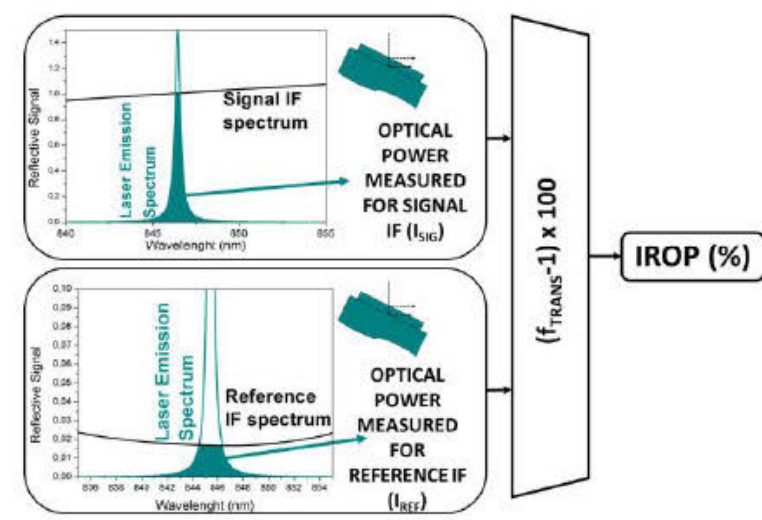

(b)

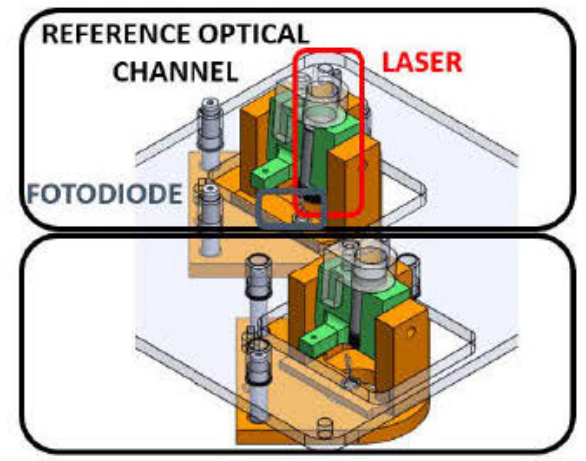

(c)

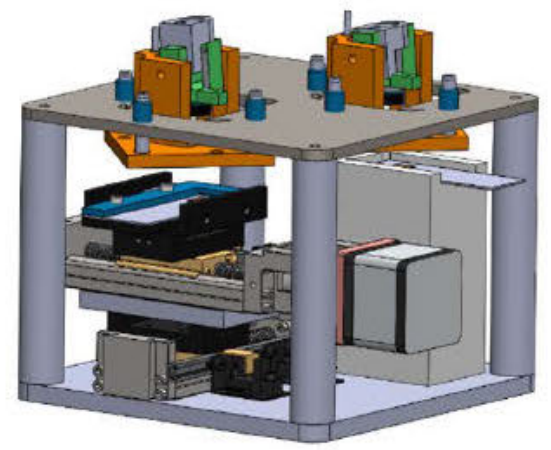

Fig. 3. (a) Read-out methodology scheme. (b) computer-aided design design for both optical channels (reference and signal), based on a laser and a photodiode implemented in a mechanical platform to properly line-up the light beam. (c) CAD design for the read-out system based on the optical channels and an XY-positioning stage.

As it was mentioned earlier, the main goal of this development is to carry out the screening of different optimization steps of immunoassays. Therefore, the experiments presented in the next lines will analyze several biofunctionalization protocols and will test different concentrations of the target protein. This paper tests the performance of the IROP-based system developed within this paper and its main advantages as an immunoassays screening tool.

\section{EXPERIMENTAL}

\section{A. Immobilization Protocols for Anti-C-Reactive}

The first step of the direct immunoassay is the biofunctionalization of the sensing surface. In this paper, four incubation protocols for the anti-C-reactive immobilization are tested, with and without linker, for the correct orientation of the antibody. Table I collects the most relevant parameters for each incubation step included in the protocols analyzed.
TABLE I

IMMOBILIZATION PROTOCOLS FOR ANTI-CRP ANTIBODY

\begin{tabular}{lll}
\hline Protocol & \multicolumn{1}{c}{$\begin{array}{c}\text { Linker protein incubation } \\
\text { parameters }\end{array}$} & \multicolumn{1}{c}{$\begin{array}{c}\text { Antibody incubation } \\
\text { parameters }\end{array}$} \\
\hline $\mathrm{A}$ & A-protein, $[\mathrm{C}]=20 \mu \mathrm{g} / \mathrm{mL}$, & {$[\mathrm{C}]=100 \mu \mathrm{g} / \mathrm{mL}, 2$ hours at } \\
& 30 min at 37 degrees, & 37 degrees, $\mathrm{v}=10 \mu \mathrm{L}$ per cell \\
& $\mathrm{v}=3 \mu \mathrm{L}$ per cell & {$[\mathrm{C}]=100 \mu \mathrm{g} / \mathrm{mL}, 2$ hours at } \\
$B$ & No linker & 37 degrees, $\mathrm{v}=10 \mu \mathrm{L}$ per cell \\
& & {$[\mathrm{C}]=100 \mu \mathrm{g} / \mathrm{mL}$, overnight at } \\
$C$ & A-protein, $[\mathrm{C}]=20 \mu \mathrm{g} / \mathrm{mL}$, & 4 degrees, $\mathrm{v}=10 \mu \mathrm{L}$ per cell \\
& 30 min at 37 degrees, & \\
& $\mathrm{v}=3 \mu \mathrm{L}$ per cell & {$[\mathrm{C}]=100 \mu \mathrm{g} / \mathrm{mL}$, overnight at } \\
$D$ & No linker & 4 degrees, $\mathrm{v}=10 \mu \mathrm{L}$ per cell \\
\hline
\end{tabular}

These immobilization protocols are commonly used in several standard techniques such as ELISA, western blot lateral flow-based devices, and microarray [43]-[46], in which the sensing surface is a nitrocellulose membrane that immobilizes the target biomolecules by physical absorption, and therefore, similar to the surface of the SCs presented within this paper.

After the incubation of each sample, the chip surface is rinsed with Milli-Q water and dried it with clean particle-free air. Once the sensing surface is biofunctionalized, $10 \mu \mathrm{g} / \mathrm{mL}$ of CRP are incubated for $1 \mathrm{~h}$ at $37^{\circ}$, using $10 \mu \mathrm{L}$ of sample per measurement, and compare the $\triangle I R O P(\%)$ signal for the biomolecule recognition obtained in each protocol, which identifies the best immobilization technique within the tested ones.

Fig. 4(a) shows the $\triangle I R O P(\%)$ signal for each step, comparing different protocols studied, meanwhile, Fig. 4(b) shows the $\triangle$ IROP (\%) signal for the recognition of CRP. As it can be observed, immobilization protocols defined as B and D present the highest recognition signal, around $60 \%-70 \% \Delta \mathrm{IROP}$ for $10 \mu \mathrm{g} / \mathrm{mL}$ of CRP. This result agrees with a higher value for the antibody immobilization [Fig. 1(a)] in the not oriented antibody protocols: $-250 \% \Delta \mathrm{IROP}$ for $\mathrm{A}$ and $\mathrm{C}$ protocols versus $-450 \% \Delta \mathrm{IROP}$ for B and D protocols. Protocols B over $\mathrm{D}$ will continue the screening due to the reduction in time of incubation.

\section{B. Recognition of C-Reactive Protein for Different Immobilization Techniques}

Once selected the most promising immobilization protocol, a comparison for the $\triangle I R O P(\%)$ signal obtained for different CRP concentrations is carried out. Since the definition of a patient with cardiovascular risk is over $1 \mu \mathrm{g} / \mathrm{mL}$ of CRP [25], [26], the concentrations selected for this comparison are: $0.5,1$, and $10 \mu \mathrm{g} / \mathrm{mL}$.

The biofunctionalization steps are the ones defined in Table I for protocol B. To perform the recognition of CRP; $10 \mu \mathrm{L}$ per cell of each concentration is incubated and now during $2 \mathrm{~h}$ for enhancing the recognition signal at $37^{\circ}$ in a humid environment. At the same time, bovine serum albu$\min$ (BSA) is used in the same concentrations and incubation conditions as CRP. This protein is unspecific to the CRP antibody immobilized in the sensing surface, and it can be used as a negative control to check the unspecific absorption of biomolecules in the recognition. Fig. 5 shows the $\triangle I R O P(\%)$ signal obtained for each concentration analyzed, 
(a)
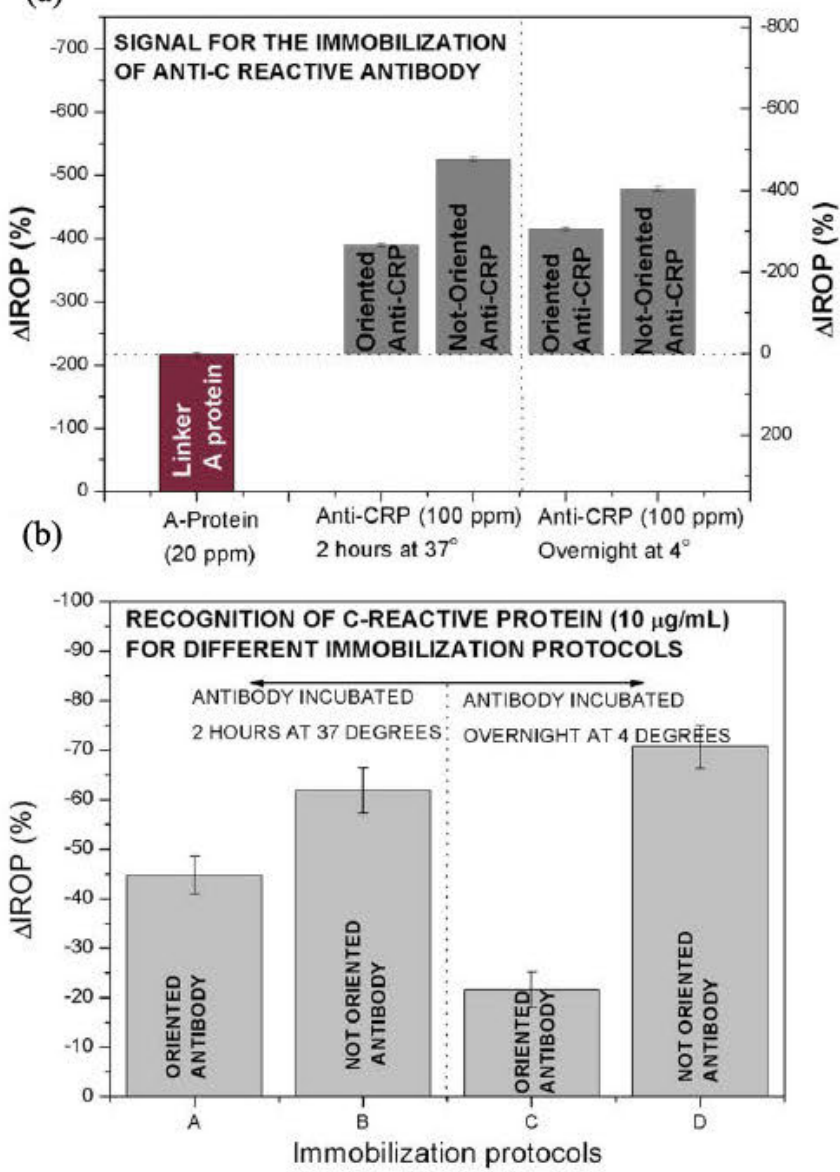

Fig. 4. (a) $\triangle I R O P(\%)$ signal for the immobilization of A-protein and for different incubation protocols used in the immobilization of anti-C-reactive antibody. (b) Comparison of the $\triangle \mathrm{IROP}(\%)$ signal for the recognition of $10 \mathrm{ppm}$ of CRP in each evaluated protocol.

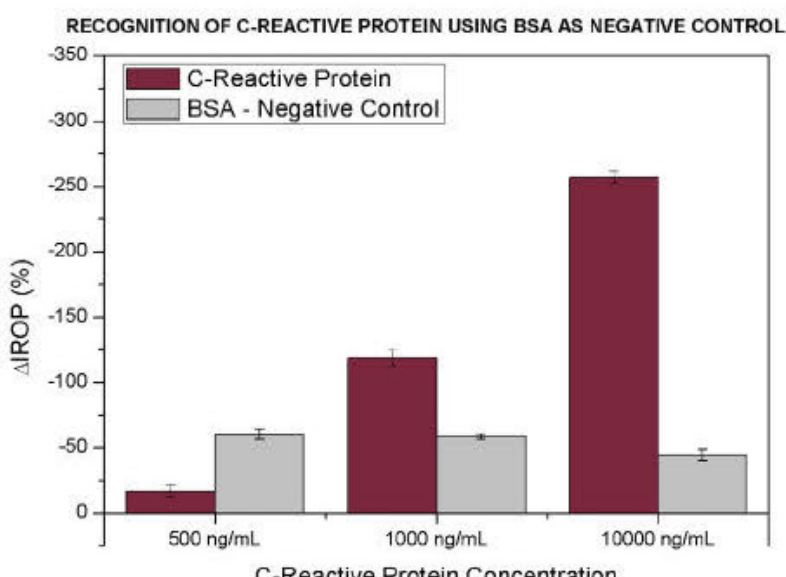

Fig. 5. $\triangle \mathrm{IROP}(\%)$ signal for different concentrations of CRP in comparison with BSA as a negative control.

verifying how immobilization protocol $\mathrm{B}$ allows differentiating between healthy and at risk patients. The $\triangle \mathrm{IROP}(\%)$ value obtained for $10 \mu \mathrm{g} / \mathrm{mL}$ of CRP ( $-257 \% \Delta$ IROP) is higher than in previous results in Fig. 3(b) $(-62 \% \Delta$ IROP) due to the increment in the incubation time (from 1 to $2 \mathrm{~h}$ ).

Fig. 5 also shows the comparison between the recognition of CRP and BSA as a negative control. The $\triangle \mathrm{IROP}(\%)$ signal obtained for BSA is stable along the assay and it can be considered as an estimation measurement for the matrix effect usually found in real samples. As can be seen in the figure, only an average of $-54.5 \% \Delta$ IROP signal is due to unspecific binding.

For the presented results, read-out signal fluctuations due to temperature variation were considered negligible under the experimental conditions.

\section{CONCLUSION}

In this paper, a cost-effective tool for the optimization of different steps involved in an immunoassay is described. The optical, label-free point-of-care device developed achieves an improvement in sensitivity in comparison with previous work and reduces significantly the sample volume and, therefore, the reagent cost employed in the recognition of target molecules. To reach this, a laser diode module replaces the LED used as a light source and a redesign for the FP interferometers is implemented. The new approach for the signal interferometer based on three SCs of $100 \mu \mathrm{m}$ of diameter allows reducing the sample volume and reagent concentration by reducing the sensing area. On the other hand, the redesign for the reference interferometer and the optical power and narrow interrogation band of the laser diode increase the device sensitivity in almost $50 \times$ in comparison with our previous point of care device device.

These developments are tested by the screening of a direct immunoassay for the recognition of CRP, monitoring different immobilization protocols of the anti-C-reactive antibody and measuring different concentrations for the target protein. It is important to highlight that only $10 \mu \mathrm{L}$ of sample is used in each measurement carried out.

\section{ACKNOWLEDGMENT}

The authors would like to thank M. Vicente and M. Domingo for the support in the device implementation. They would also like to thank D. López-Romero and Y. Ramirez for the support in the transducers fabrication.

\section{REFERENCES}

[1] M. A. Arugula and A. Simonian, "Novel trends in affinity biosensors: Current challenges and perspectives," Meas. Sci. Technol., vol. 25, no. 3, p. 032001, Mar. 2014.

[2] G. Zanchetta, R. Lanfranco, F. Giavazzi, T. Bellini, and M. Buscaglia, "Emerging applications of label-free optical biosensors," Nanophotonics, vol. 6, no. 4, pp. 627-645, Jan. 2017.

[3] P. B. Luppa, A. Bietenbeck, C. Beaudoin, and A. Giannetti, "Clinically relevant analytical techniques, organizational concepts for application and future perspectives of point-of-care testing," Biotechnol. Adv., vol. 34, no. 3, pp. 139-160, 2016.

[4] Y. Kostov and G. Rao, "Low-cost optical instrumentation for biomedical measurements," Rev. Sci. Instrum., vol. 71, no. 12, pp. 4361-4374, Nov. 2000.

[5] Y.-S. Sun, "Optical biosensors for label-free detection of Biomolecular interactions," Instrum. Sci. Technol., vol. 42, no. 2, pp. 109-127, Mar. 2014.

[6] M. Ahmed et al., "Role of Raman spectroscopy in bio and agriculture as an optical diagnostic tool," in Proc. Prog. Electromagn. Res. Symp. (PIERS), 2016, p. 2326.

[7] Y. Li et al., "High sensitive and selective Escherichia coli detection using immobilized optical fiber microprobe," in Proc. Opt. Fiber Sensors Conf., 2017, pp. 1-4, Paper 103232P. 
[8] H. von Horsten et al., "A compact, high resolution multichannel optical interrogator based on an integral field spectrometer for label-free monitoring of toxins in oceanic water," in Proc. Conf. Lasers ElectroOpt. Eur. Quantum Electron. Conf. (CLEO/Europe-EQEC), 2017, pp. $1-4$.

[9] S. R. Raz, M. G. E. G. Bremer, W. Haasnoot, and W. Norde, "Labelfree and multiplex detection of antibiotic residues in milk using imaging surface plasmon resonance-based immunosensor," Anal. Chem., vol. 81, no. 18, pp. 7743-7749, Sep. 2009.

[10] S. H. Ohk, O. K. Koo, T. Sen, C. M. Yamamoto, and A. K. Bhunia, "Antibody-aptamer functionalized fibre-optic biosensor for specific detection of Listeria monocytogenes from food," J. Appl. Microbiol., vol. 109, no. 3, pp. 808-817, Sep. 2010.

[11] N. Khansili, G. Rattu, and P. M. Krishna, "Label-free optical biosensors for food and biological sensor applications," Sens. Actuators B, Chem., vol. 265, pp. 35-49, Jul. 2018.

[12] S. Rau, U. Hilbig, and G. Gauglitz, "Label-free optical biosensor for detection and quantification of the non-steroidal anti-inflammatory drug diclofenac in milk without any sample pretreatment," Anal. Bioanal. Chem., vol. 406, no. 14, pp. 3377-3386, May 2014.

[13] M. I. Zibaii, H. Latifi, A. Asadollahi, A. H. Bayat, L. Dargahi, and A. Haghparast, "Label free fiber optic apta-biosensor for in-vitro detection of dopamine," J. Lightw. Technol., vol. 34, no. 19, pp. 4516-4524, Oct. 1, 2016.

[14] Y. Fang, "Label-free cell-based assays with optical biosensors in drug discovery," Assay Drug Develop. Technol., vol. 4, no. 5, pp. 583-595, Oct. 2006.

[15] Y. Demircan et al., "Label-free detection of leukemia cells with a lab-on-a-chip system integrating dielectrophoresis and CMOS imaging," in Proc. 18th Int. Conf. Solid-State Sens., Actuators Microsyst. (TRANSDUCERS), Jun. 2015, pp. 1589-1592.

[16] P. Deng, C. Song, and L. Que, "Label-free monitoring of Alzheimer's disease biomarkers in cerebrospinal fluid," in Proc. IEEE 17th Int. Conf. Nanotechnol. (IEEE-NANO), Jul. 2017, pp. 1074-1077.

[17] M. Barozzi et al., "Optical fiber sensors for label-free DNA detection," J. Lightw. Technol., vol. 35, no. 16, pp. 3461-3472, Aug. 15, 2017.

[18] C. Lei et al., "High-throughput, label-free, multivariate cell analysis with optofluidic time-stretch microscopy," in Proc. Conf. Lasers Electro-Opt. Pacific Rim (CLEO-PR), Jul. 2017, pp. 1-4.

[19] V. K. Jagannadh, M. D. Mackenzie, P. Pal, A. K. Kar, and S. S. Gorthi, "Imaging flow cytometry with femtosecond laser-micromachined glass microfuidic channels," IEEE Sel. Topics Quantum Electron. J., vol. 21, no. 4, Jul./Aug. 2015, Art. no. 6800106.

[20] S. Jahns and M. Gerken, "Imaging label-free biosensor for multiplexed protein detection," in Proc. 18th Int. Conf. Transparent Opt. Netw. (ICTON), Jul. 2016, pp. 1-4.

[21] Y. Gu, Y. Yang, J. Zhang, S. Ge, Z. Tang, and X. Qiu, "Point-ofcare test for C-reactive protein by a fluorescence-based lateral flow immunoassay," Instrum. Sci. Technol., vol. 42, no. 6, pp. 635-645, Nov. 2014.

[22] M. Alvarez, D. Fariña, A. M. Escuela, J. R. Sendra, and L. M. Lechuga, "Development of a surface plasmon resonance and nanomechanical biosensing hybrid platform for multiparametric reading," Rev. Sci. Instrum., vol. 84, no. 1, p. 15008, Jan. 2013.

[23] D. Wang et al., "A high-throughput surface plasmon resonance biosensor based on differential interferometric imaging," Meas. Sci. Technol., vol. 23, no. 6, p. 065701, Jun. 2012.

[24] S. Rampazzi, G. Danese, F. Leporati, and F. Marabelli, "A localized surface plasmon resonance-based portable instrument for quick on-site biomolecular detection," IEEE Trans. Instrum. Meas., vol. 65, no. 2, pp. 317-327, Feb. 2016.

[25] M. B. Pepys and G. M. Hirschfield, "C-reactive protein: A critical update," J. Clin. Invest., vol. 111, no. 12, pp. 1805-1812, 2003.

[26] S. Black, I. Kushner, and D. Samols, "C-reactive protein," J. Biol. Chem., vol. 279, no. 47, pp. 48487-48490, 2004.

[27] M. H. F. Meyer, M. Hartmann, and M. Keusgen, "SPR-based immunosensor for the CRP detection-A new method to detect a well known protein,” Biosensors Bioelectron., vol. 21, no. 10, pp. 1987-1990, 2006.

[28] T. Bryan, X. Luo, P. R. Bueno, and J. J. Davis, "An optimised electrochemical biosensor for the label-free detection of C-reactive protein in blood," Biosensors Bioelectron., vol. 39, no. 1, pp. 94-98, 2013.

[29] Y.-N. Yang, H.-I. Lin, J.-H. Wang, S.-C. Shiesh, and G.-B. Lee, "An integrated microfluidic system for C-reactive protein measurement," Biosensors Bioelectron., vol. 24, no. 10, pp. 3091-3096, 2009.
[30] Z. H. Ibupoto, N. Jamal, K. Khun, and M. Willander, "Development of a disposable potentiometric antibody immobilized $\mathrm{ZnO}$ nanotubes based sensor for the detection of C-reactive protein," Sens. Actuators B, Chem., vols. 166-167, pp. 809-814, May 2012.

[31] H. W. Choi, Y. Sakata, Y. Kurihara, T. Ooya, and T. Takeuchi, "Label-free detection of C-reactive protein using reflectometric interference spectroscopy-based sensing system," Anal. Chim. Acta, vol. 728, pp. 64-68, May 2012.

[32] H. Chammem, I. Hafaid, O. Meilhac, F. Menaa, L. Mora, and A. Abdelghani, "Surface plasmon resonance for C-reactive protein detection in human plasma," J. Biomater. Nanobiotechnol., vol. 5, pp. 153-158, Jul. 2014.

[33] M. Holgado et al., "Towards reliable optical label-free point-ofcare (PoC) biosensing devices," Sens. Actuators B, Chem., vol. 236, pp. 765-772, Nov. 2016.

[34] M. Holgado, F. J. Sanza, A. López, Á. Lavín, R. Casquel, and M. F. Laguna, "Description of an advantageous optical label-free biosensing interferometric read-out method to measure biological species," Sensors, vol. 14, no. 2, pp. 3675-3689, 2014.

[35] M. T. Aguilar-Gama et al., "Structure and refractive index of thin alumina films grown by atomic layer deposition," J. Mater. Sci., Mater. Electron., vol. 26, no. 8, pp. 5546-5552, 2015.

[36] C. Barbos et al., "Characterization of $\mathrm{Al}_{2} \mathrm{O}_{3}$ thin films prepared by thermal ALD," Energy Procedia, vol. 77, pp. 558-564, Aug. 2015.

[37] J. Vörös, "The density and refractive index of adsorbing protein layers," Biophys. J., vol. 87, no. 1, pp. 553-561, 2004.

[38] Á. Lavín, R. Casquel, F. J. Sanza, M. F. Laguna, and M. Holgado, "Efficient design and optimization of bio-photonic sensing cells (BICELLs) for label free biosensing," Sens. Actuators B, Chem., vol. 176, pp. 753-760, Jan. 2013.

[39] B. Santamaría et al., "Development towards compact nitrocellulosebased interferometric biochips for dry eye MMP9 label-free in-situ diagnosis," Sensors, vol. 17, no. 6, p. 1158, 2017.

[40] R. Espinosa et al., "A proof-of-concept of label-free biosensing system for food allergy diagnostics in biophotonic sensing cells: Performance comparison with ImmunoCAP,' Sensors, vol. 18, no. 8, p. 2686, Aug. 2018.

[41] A. K. Trilling, J. Beekwilder, and H. Zuilhof, "Antibody orientation on biosensor surfaces: A minireview," Analyst, vol. 138, no. 6, pp. 1619-1627, Feb. 2013.

[42] J. W. Haycock, "Polyvinylpyrrolidone as a blocking agent in immunochemical studies," Anal. Biochem., vol. 208, no. 2, pp. 397-399, Feb. 1993.

[43] L. Bode, L. Beutin, and H. Köhler, "Nitrocellulose-enzyme-linked immunosorbent assay (NC-ELISA) - A sensitive technique for the rapid visual detection of both viral antigens and antibodies," J. Virol. Methods, vol. 8, nos. 1-2, pp. 111-121, Feb. 1984.

[44] H. Towbin, T. Staehelin, and J. Gordon, "Electrophoretic transfer of proteins from polyacrylamide gels to nitrocellulose sheets: Procedure and some applications," Proc. Nat. Acad. Sci. USA, vol. 76, no. 9, pp. 4350-4354, Sep. 1979.

[45] E. M. Fenton, M. R. Mascarenas, G. P. López, and S. S. Sibbett, "Multiplex lateral-flow test strips fabricated by two-dimensional shaping," ACS Appl. Mater. Interfaces, vol. 1, no. 1, pp. 124-129, Jan. 2009.

[46] S.-K. Leivonen et al., "Protein lysate microarray analysis to identify microRNAs regulating estrogen receptor signaling in breast cancer cell lines," Oncogene, vol. 28, no. 44, pp. 3926-3936, Nov. 2009. 